SHORT REPORT

\title{
Pathological yawning as a presenting symptom of brain stem ischaemia in two patients
}

\author{
L Cattaneo, L Cucurachi, E Chierici, G Pavesi
}

Two cases of brain stem stroke involving the upper pons and the ponto-mesencephalic junction presented with transient excessive pathological yawning, associated with gait ataxia and in one subject with upper limb and facial hemiparesis. A causal relation is hypothesised between the brain stem lesion and pathological yawning, possibly related to denervation hypersensitivity of a putative brain stem yawn centre. Excessive yawning may herald brain stem ischaemia.

Y awning is a very common and phylogenetically ancient behavioural event that occurs in vertebrates under different conditions. A yawn consists of a stereotyped behavioural pattern that begins with an inspiration associated with marked dilatation of the pharynx. At the peak of inspiration there are associated facial movements and the final part of yawning is passive rapid expiration. During yawning a coordinated sequence of events takes place involving facial, oropharyngeal, tongue, and respiratory muscles, associated with activity in the axial extensor and limb extensor muscles and with autonomic changes characterised by an increased parasympathetic outflow. ${ }^{1}$ The physiological stimuli that give rise to the yawning response and its functional significance are not clear. It has been shown that yawning frequency is not modified by hypercapnia or by pure oxygen breathing; it does not seem, therefore, to have a straightforward respiratory function. ${ }^{2}$ Yawning occurs preferentially in conditions of low vigilance and causes transient increases in arousal as indicated by EEG desynchronisation, though an active role in the maintenance of arousal has not been demonstrated. The social importance of yawning is particularly evident in mammals, where it seems to have a communicative role in conditions of decreased vigilance. $^{2}$ The neural structures that control yawning are presumably located in the brain stem near to or within other respiratory and vasomotor centres, especially those that control facial mimicry, mastication, throat movements, respiration, and possibly stretching. ${ }^{3}$ Excessive or pathological yawning is defined as a compulsive, repetitive action that is not triggered by appropriate stimuli such as fatigue or boredom. We describe here two cases of excessive yawning behaviour associated with ischaemic lesions in the brain stem.

\section{CASE REPORTS}

\section{Patient 1}

A 74 year old man was admitted to our clinic complaining of unsteadiness of stance and gait, lasting for 12 hours. The patient described an acute onset of excessive, repetitive, compulsive yawning that he was unable to control; the yawns were repeated at a frequency of about 3/minute. Forty minutes later the patient also noticed gait ataxia and inability to stand without assistance. When admitted to the hospital, neurological examination showed a slight intention tremor of the left arm and slight dysmetria in the finger-nose manoeuvre; no limb weakness was present and tendon reflexes were normal. The patient was able to stand and walk but gait was possible only with broad based, irregular steps and leftward veering. The cranial nerves were unaffected and nystagmus was not present. His state of vigilance remained normal. He reported abnormally frequent yawning for three days following the acute onset, with progressively longer intervals between one yawning act and the next. Three days later, neurological examination was normal and all symptoms had disappeared.

Magnetic resonance imaging (MRI), done three days after the onset of the neurological deficit, showed a small hyperintense lesion in the left paramedian region of the middle pons on fluid attenuated inversion recovery (FLAIR) images (fig l, left panel). The lesion was also evident as an area of hyperintense signal in T2 weighted images. At a three months follow up the patient was free of all symptoms.

\section{Patient 2}

A 66 year old woman presented with the acute onset of imbalance of stance and gait, followed two hours later by a single episode of vomiting and by weakness of the left upper limb. She reported an episode of unjustified excessive yawning, at a frequency of approximately one event every two minutes, which began 20 to 30 minutes before the neurological symptoms. On admission to hospital, clinical examination showed a slight left lower facial paresis, horizontal nystagmus beating leftwards, and a right sided internuclear ophthalmoplegia. A pronator drift in antigravity posture and clumsiness in distal finger movements were observed in the left upper limb. Slight proximal weakness was present in the left lower limb as well. Tendon reflexes were normally elicitable in the four limbs. An extensor plantar response was present on the left side. Finger-nose and reaching manoeuvres showed slight dysmetria on the right and could not be evaluated on the left because of the motor deficit. No sensory deficit could be observed in the trigeminal or the somatic territory. The patient had a broad based gait and a marked left lateropulsion on standing. Vigilance was normal. MRI done five days after the onset of symptoms showed right pontine ischaemia (fig l, right panel) and MRI-angiography showed a pseudo-occlusive stenosis of the basilar artery. The frequency of yawning gradually decreased and returned to normal within 36 hours. The motor deficit on the left side and the gait ataxia was still present, though moderately improved, at three weeks after symptom onset.

\section{DISCUSSION}

We describe here, for the first time, patients with brain stem ischaemic stroke presenting with excessive yawning. The possible causal relation between the brain stem lesion and

Abbreviation: FLAIR, fluid attenuated inversion recovery 


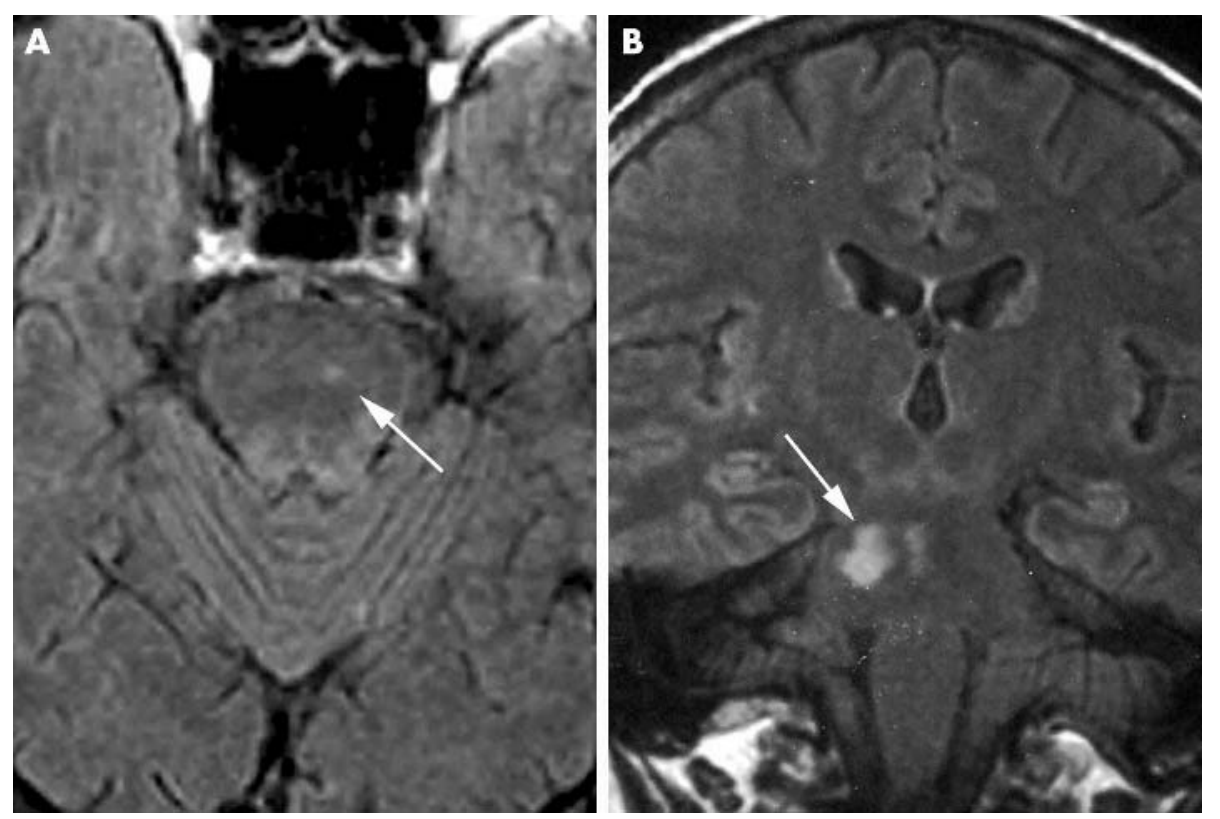

Figure 1 Fluid attenuated inversion recovery (FLAIR) brain images of the two patients. (A) Patient 1: axial section showing a small hyperintense left paramedian area at the ponto-mesencephalic border. The scan was acquired at three days after the onset of symptoms. (B) Patient 2: coronal section, showing the ischaemic area in the right paramedian pons and ponto-mesencephalic border. The scan was acquired five days after the onset of symptoms.

the excessive yawning behaviour could provide useful information on the anatomical location of the neural systems controlling yawning in humans.

The central anatomical pathways subserving yawning have not been clearly defined. ${ }^{4}$ The published evidence indicates the presence in mammals of a subcortical circuit mediating the yawning phenomenon, involving the hypothalamus, the midbrain, and the reticular formation of the pons and medulla. ${ }^{2-4}$ In the rat experimentally induced excessive yawning behaviour can be produced by direct or indirect activation of the oxytocinergic neurones in the paraventricular hypothalamic nucleus, which is thought to play a primary role in initiating the yawning phenomenon. The activity of hypothalamic yawning related neurones is subject to a complex pharmacological control, being enhanced by dopamine D2 and possibly D3 agonists, nitric oxide, acetylcholine, and ACTH-MSH peptides, orexins, and serotonin and downregulated by opioids. ${ }^{5}$ Similar pharmacological mechanisms may act in humans, where D2 agonists, SSRI agents, and withdrawal from morphine exert a facilitatory effect on the yawning behaviour. Valproate overdose, imipramine, and oestrogen substitution may also cause pathological excessive yawning. ${ }^{5}$

The existence in humans of a similar putative yawning centre in the lower brain stem is suggested by lesional data. Three reports $^{6-8}$ have described patients with locked-in syndrome, with preserved yawning movements and complete volitional paralysis of the bulbar musculature. It has also been observed that yawning movements persist in anencephalic infants. ${ }^{2}$ Up to now the existence of a cortical representation of yawning has not been clearly demonstrated, though a recent brain imaging study showed the presence of an area in the posterior cingulated cortex that is activated by observation of yawning and is supposed to be involved in the well known phenomenon of contagious yawning. ${ }^{9}$

In both of our cases there was excessive yawning behaviour associated with a brain stem infarct. The lesion was located in the paramedian region in the ponto-mesencephalic junction in both cases, though the lesion in patient 2 extended much more caudally, involving also the upper half of the pons (fig 1, right panel). The clinical picture was characterised by gait ataxia in both patients, which is known to occur frequently in paramedian mesencephalic and pontine infarction. ${ }^{1011} \mathrm{~A}$ motor deficit was present only in patient 2, because of the anterior extension of the lesion. Focal brain stem lesions have already been found to cause pathological yawning. Jurko and Andy ${ }^{12}$ reported excessive yawning during hyperventilation in patients who had previously undergone thalamotomy or with recent head trauma, and concluded that it can be a sign of brain stem damage. In neither of our patients did there appear to be a facilitatory effect of hyperventilation. Arai et $a l^{13}$ reported excessive yawning in a patient with a tumour of the floor of the fourth ventricle, and Postert et al described excessive yawning as a symptom of brain stem localisation of multiple sclerosis. ${ }^{14}$ Additionally, excessive yawning has been observed in progressive supranuclear palsy, intracranial hypertension, and temporal lobe epilepsy, though in the latter it was not assigned specific value in the localisation of the epileptic focus. ${ }^{15} 16$

The exact mechanism of excessive yawning following focal brain lesions is not fully understood. Possibly the pathological behaviour is an expression of liberation from the control of more cranial structures of a putative yawning centre, caudal to the lesion, analogously to the hypothesis postulated for hiccups caused by medullary lesions, ${ }^{17}$ or for the symptom of excessive yawning behaviour in patients with amyotrophic lateral sclerosis. ${ }^{18}$ In our two patients we hypothesise also that the pathogenesis of the excessive yawning could be related to a denervation hypersensitivity mechanism. To our knowledge, this is the first report of excessive yawning after brain stem stroke and, more importantly, in both patients yawning appeared to be the first symptom of the ischaemic insult. We conclude that excessive yawning can be a presenting symptom of an acute brain stem lesion and should not be overlooked. 


\section{Authors' affiliations}

L Cattaneo, L Cucurachi, E Chierici, G Pavesi, Sezione di Neurologia, Dipartimento di Neuroscienze, Università degli Studi di Parma, Parma Italy

Competing interests: none declared

Correspondence to: Dr Luigi Cattaneo, Sezione di Neurologia, Dipartimento di Neuroscienze, Università di Parma, Via Gramsci 14, 43100 Parma, Italy; luigi.cattaneo@nemo.unipr.it

Received 1 July 2005

In revised form 11 August 2005

Accepted 11 August 2005

Published Online First 20 September 2005

\section{REFERENCES}

1 Askenasy JJ, Askenasy N. Inhibition of muscle sympathetic nerve activity during yawning. Clin Auton Res 1996;6:237-9.

2 Daquin G, Micallef J, Blin O. Yawning. Sleep Med Rev 2001:5:299-312.

3 Barbizet J. Yawning. J Neurochem 1958;21:203-9.

4 Wimalaratna HS, Capildeo R. Is yawning a brainstem phenomenon? Lancet 1988;i, 300.

5 Argiolas A, Melis MR. The neuropharmacology of yawning. Eur J Pharmacol 1998;343:1-16.
6 Bauer G, Gerstenbrand F, Hengl W. Involuntary motor phenomena in the locked-in syndrome. J Neurol 1980;223:191-8.

7 Gschwend J. [Yawning in a case with transsecting glioma of the pons (author's translation)]. Fortschr Neurol Psychiatr Grenzgeb 1977:45:652-5.

8 Krasnianski M, Gaul C, Neudecker S, et al. Yawning despite trismus in a patient with locked-in syndrome caused by a thrombosed megadolichobasilar artery. Clin Neurol Neurosurg 2003;106:44-6.

9 Platek SM, Mohamed FB, Gallup GG. Contagious yawning and the brain. Brain Res Cogn Brain Res 2005;23:448-52.

10 Kumral E, Bayulkem G, Evyapan D. Clinical spectrum of pontine infarction. Clinical-MRI correlations. J Neurol 2002;249:1659-70.

11 Kim JS, Kim J. Pure midbrain infarction: clinical, radiologic, and pathophysiologic findings. Neurology 2005;64:1227-32.

12 Jurko MF, Andy OJ. Post-lesion yawning and thalamotomy site. Appl Neurophysiol 1975;38:73-9.

13 Arai K, Kita K, Komiyama A, et al. [Progressive dysautonomia in hemangioblastoma in the region of the fourth ventricle]. No To Shinkei 1986;38:195-200.

14 Postert T, Pohlau D, Meves S, et al. Pathological yawning as a symptom of multiple sclerosis. J Neurol 1996;243:300-1.

15 Fletcher S, Cohen F, Borenstein F, et al. Yawning as a paroxysmal sign of diencephalic seizures. Arch Psychol Psychiatry Neurol 1982;43:45-54.

16 Sandyk R. Excessive yawning and progressive supranuclear palsy. Int J Neurosci 1987;34:123-4.

17 Park MH, Kim BJ, Koh SB, et al. Lesional location of lateral medullary infarction presenting hiccups (singultus). I Neurol Neurosurg Psychiatry 2005;76:95-8

18 Williams DR. The yawning reflex: an upper motor neuron sign in amyotrophic lateral sclerosis. Neurology 2000;55:1592-3. 